Atmos. Chem. Phys., 10, 2053-2061, 2010

www.atmos-chem-phys.net/10/2053/2010/

(C) Author(s) 2010. This work is distributed under

the Creative Commons Attribution 3.0 License.

\title{
Potential climatic impacts and reliability of very large-scale wind farms
}

\author{
C. Wang and R. G. Prinn
}

Center for Global Change Science and Joint Program of the Science and Policy of Global Change, Massachusetts Institute of Technology, Cambridge, MA 02139, USA

Received: 17 August 2009 - Published in Atmos. Chem. Phys. Discuss.: 14 September 2009

Revised: 17 December 2009 - Accepted: 10 February 2010 - Published: 22 February 2010

\begin{abstract}
Meeting future world energy needs while addressing climate change requires large-scale deployment of low or zero greenhouse gas (GHG) emission technologies such as wind energy. The widespread availability of wind power has fueled substantial interest in this renewable energy source as one of the needed technologies. For very large-scale utilization of this resource, there are however potential environmental impacts, and also problems arising from its inherent intermittency, in addition to the present need to lower unit costs. To explore some of these issues, we use a threedimensional climate model to simulate the potential climate effects associated with installation of wind-powered generators over vast areas of land or coastal ocean. Using wind turbines to meet $10 \%$ or more of global energy demand in 2100 , could cause surface warming exceeding $1{ }^{\circ} \mathrm{C}$ over land installations. In contrast, surface cooling exceeding $1^{\circ} \mathrm{C}$ is computed over ocean installations, but the validity of simulating the impacts of wind turbines by simply increasing the ocean surface drag needs further study. Significant warming or cooling remote from both the land and ocean installations, and alterations of the global distributions of rainfall and clouds also occur. These results are influenced by the competing effects of increases in roughness and decreases in wind speed on near-surface turbulent heat fluxes, the differing nature of land and ocean surface friction, and the dimensions of the installations parallel and perpendicular to the prevailing winds. These results are also dependent on the accuracy of the model used, and the realism of the methods
\end{abstract}

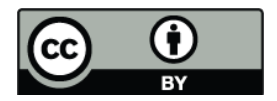

Correspondence to: C. Wang (wangc@mit.edu) applied to simulate wind turbines. Additional theory and new field observations will be required for their ultimate validation. Intermittency of wind power on daily, monthly and longer time scales as computed in these simulations and inferred from meteorological observations, poses a demand for one or more options to ensure reliability, including backup generation capacity, very long distance power transmission lines, and onsite energy storage, each with specific economic and/or technological challenges.

\section{Introduction}

World energy demand is predicted to increase from $\sim 430$ EJ/year $(14 \mathrm{TW})$ in 2002 to $\sim 1400 \mathrm{EJ} /$ year $(44 \mathrm{TW})$ in 2100 (Reilly and Paltsev, 2007). Any effective energy contributor needs to be implemented on a very large scale (e.g. provide $10 \%$ of the year 2100 demand). Among the current energy technologies with low or zero greenhouse gas (GHG) emissions, electrical generation using wind turbines is percentage-wise the fastest growing energy resource worldwide. In the US, it has grown from $1.8 \mathrm{GW}$ of capacity in 1996 to more than $11.6 \mathrm{GW}(\sim 0.37 \mathrm{EJ} /$ year $)$ in 2006 , but this is still negligible compared to future energy demand.

The solar energy absorbed by the Earth is converted into latent heat (by evaporation), gravitational potential energy (by atmospheric expansion), internal energy (by atmospheric and oceanic warming, condensation), or kinetic energy (e.g by convective and baroclinic instabilities) (Lorenz, 1967). Averaged globally, internal energy, gravitational potential energy, latent heat, and kinetic energy comprise about 70.4, $27.05,2.5$, and $0.05 \%$ respectively of the total atmospheric

Published by Copernicus Publications on behalf of the European Geosciences Union. 
energy (Peixoto and Oort, 1992). However, only a small fraction of the already scarce kinetic energy is contained in the near surface winds that then produce small-scale turbulent motions due to surface friction. Eventually the turbulent motions downscale to molecular motions, thus converting bulk air kinetic energy to internal energy.

However, it is not the size of these energy reservoirs, but the rate of conversion from one to another, that is more relevant here. The global average rate of conversion of largescale wind kinetic energy to internal energy near the surface is about $1.68 \mathrm{~W} / \mathrm{m}^{2}$ ( $860 \mathrm{TW}$ globally) in our model calculations. This is only about $0.7 \%$ of the average net incoming solar energy of $238 \mathrm{~W} / \mathrm{m}^{2}$ (122 PW globally) (Lorenz, 1967; Peixoto and Oort, 1992). The magnitude of this rate when wind turbines are present is expected to differ from this, but not by large factors. The widespread availability of wind power has fueled substantial interest in harnessing it for energy production (e.g. Carter, 1926; Hewson, 1975; Archer and Jacobson, 2003). Wind turbines convert wind power into electrical power. However, the turbulence near the surface, which also feeds on wind power, is critical for driving the heat and moisture exchanges between the surface and the atmosphere that play an important role in determining surface temperature, atmospheric circulation and the hydrological cycle.

Because of the low output ( $\sim \mathrm{MW}$ ) of individual wind turbines, one needs to install a large number of the devices to generate a substantial amount of energy. For example, presuming these turbines are effectively generating at full capacity only $1 / 3$ of the time, about 13 million of them are needed to meet an energy output of $140 \mathrm{EJ} / \mathrm{year}$ (4.4 TW), and they would occupy a continental-scale area. While the amount of energy gained from global deployment of surface wind power may be small relative to the $860 \mathrm{TW}$ available globally, the accompanying climate effects may not be negligible. A previous study using atmospheric general circulation models with fixed sea surface temperatures suggests that the climatic perturbation caused by a large-scale land installation of wind turbines can spread well beyond the installation regions (Keith et al., 2004).

\section{Methods}

To explore the potential climate impacts of very largescale windfarms, we use, for the first time, a fully coupled atmosphere-ocean-land system model, specifically the Community Climate Model Version 3 of the US National Center for Atmospheric Research with a mixed layer ocean (Kiehl et al., 1998). In order to isolate the climate effects of wind turbines from those due to greenhouse gas increases, all runs were carried out with current greenhouse gas levels. The chosen T42 spatial spectral resolution provides an approximately 2.8 by 2.8 degree grid point spacing in the horizontal, and there are 18 vertical layers.
Seven model runs with 60-year durations were carried out and are reported here. Each run takes about 40 years to reach climatic steady states that approximately repeat annually after that. Four of the five runs (denoted VL, L, H, and $\mathrm{VH}$ ) used different schemes to simulate the wind turbine effects over land, while another run (REF) excludes any wind turbine effects and thus serves as the control or reference. Besides the land installation simulations, we have also conducted two additional runs (denoted $\mathrm{OL}$ and $\mathrm{OH}$ ) in which we simulate installing wind turbines over all coastal regions between $60^{\circ} \mathrm{S}$ and $74^{\circ} \mathrm{N}$ in latitude where the ocean depth is shallower than $200 \mathrm{~m}$. As before, comparisons of the oceanic wind turbine runs with the REF run serve to isolate the climate effects of the wind turbines. Unless otherwise indicated, the means of the last 20 years (years 41-60) of each of the model integrations are used in the analyses.

Previous model studies of wind farms of various scales have used methods to increase the surface roughness to simulate the aerodynamic effect of wind turbines (Frandsen, 1992; Baidya Roy et al., 2004; Keith et al., 2004; also see the review by Crespo et al., 1999). We adopt the same general approach, but use model-provided parameters for objects similar to wind turbines. We selected the global land regions covered by grass (including cold $\mathrm{C} 3$ and warm $\mathrm{C} 4$ ) and shrub (including evergreen and deciduous) to be the sites for installation of the wind turbines over the land. This choice is influenced by the generally lower economic value and high wind speeds over such lands, but future studies might investigate alternative strategies. The wind turbine effect is simulated specifically by modifying the model surface roughness and/or displacement height coefficients over the global grass and shrub regions in the land model of the CCM3 system. The selected roughness and displacement height in the four wind turbine runs are: Run VL, $0.12 \mathrm{~m}$ (double the original value) and $0.34 \mathrm{~m}$ (unchanged); Run L, $0.16 \mathrm{~m}$ (arbitrary) and $0.34 \mathrm{~m}$; Run H, $0.75 \mathrm{~m}$ (arbitrary, close to the value of $0.77 \mathrm{~m}$ of the needle leaf deciduous tree in the model) and $0.34 \mathrm{~m}$; and Run VH, $2.62 \mathrm{~m}$ and $23.45 \mathrm{~m}$ (based on the evergreen forest in the model). In the ocean-based experiments, an additional surface drag of 0.007 and 0.001 over the installed regions has been applied in the Runs OH and OL, respectively, to simulate the wind turbine effect on wind power extraction. The former value is about the same as a reported measurement over mesoscale windfarms (see Keith et al., 2004) while the latter is about double the average sea surface roughness (Peixoto and Oort, 1992). Note that the equations describing the atmosphere-ocean interfacial interactions in the model are highly parameterized and defining a formulation to mimic wind turbines with equivalent realism to the one used for the land-based experiments is difficult. Therefore, the two ocean experiments are for exploratory purposes only. 
Except for the changes made to the surface roughness or displacement height described above, we keep all other surface properties in these regions identical to their standard CCM3 settings. The model calculates the actual surface properties based on weighted values over all surface types in a given grid. Our method for land installations avoids changing uniformly the above two surface properties of a given model grid to those of a modeled wind farm unless one or both of the two selected surface types (grass, shrub) dominate the grid.

The rate of conversion of large-scale kinetic energy to turbulent kinetic energy can be described by a term in the equation for the change in the mean flow kinetic energy per unit volume of air (KE) with time $t$ (Stull, 1988):

$\frac{d \mathrm{KE}}{d t}=-\rho \overline{u_{i}^{\prime} u_{j}^{\prime}} \frac{\partial U_{i}}{\partial x_{j}}=\tau_{i, j} \frac{\partial U_{i}}{\partial x_{j}}$.

Here, $i, j=1,2,3$ are the three directions of the spatial coordinates, $x, U$ is the mean wind speed, $u^{\prime}$ is the deviation of the actual wind from the mean (so that it reflects the turbulent motions), $\rho$ is the air density, and $\tau$ is the surface stress. The same term exists in the equation of change of turbulent kinetic energy but with an opposite sign. The surface stress is derived in the land surface model (LSM) or the mixed-layer ocean model of CCM3 as a function of surface properties including roughness and displacement height. The change in the rate of downward transport of cascaded kinetic energy due to the simulated wind turbine effects are calculated continuously at each model time step ( $20 \mathrm{~min}$ ) by comparing the surface stress values derived with and without the perturbed surface roughness and/or displacement, respectively. These calculated changes are then used to calculate the uptake of wind power by the simulated wind turbines which is then partially converted to the actual electrical power output.

The various changes in surface properties lead to an increase of surface momentum drag and a decrease of local near-surface wind speed. The changes in surface momentum drag in Run L were up to 0.0025 , depending on the dominance of the grass and shrub types in the given model grid (Fig. 1). This effect is enhanced in Runs $\mathrm{H}$ and $\mathrm{VH}$, and reduced in VL. We install the wind turbines over 58 million $\mathrm{km}^{2}$ of shrub and grass lands in the major continents, or over 10 million $\mathrm{km}^{2}$ of the global coastal oceans where the depths are less than $200 \mathrm{~m}$ (Fig. 1). The relevant model parameters were derived in short trial runs to remove the amount of near-surface atmospheric kinetic energy needed to match various energy production targets. We make no specific assumptions about the type and spacing of these wind turbines; our interest is only in determining the impacts of removing the kinetic energy from the near-surface atmosphere needed to drive them.
Locations of Land and Offshore "Windmills" Installation

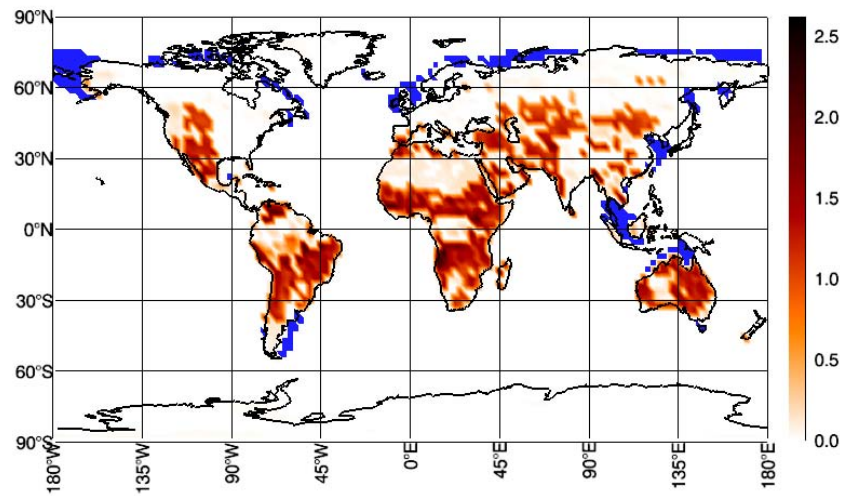

Fig. 1. Locations of land installations are indicated by the modeled change of surface drag coefficient (non-dimensional) averaged over the final 20 years of the 60-year Run L (see color code on right hand side). The drag values have been scaled by a factor of 1000 . Also shown are the locations of offshore installation regions where the ocean depth is shallower than $200 \mathrm{~m}$ (blue shading).

\section{Results}

In Run L with a moderate change in the surface roughness over the installed land regions, the reduction of wind power due to the wind turbines is about $20 \mathrm{TW}$, or $630 \mathrm{EJ} / \mathrm{yr}$, which is about $2.3 \%$ of the total rate of conversion of mean flow to turbulent kinetic energy at the Earth's surface and $23 \%$ of the conversion rate over the actual areas of the wind turbine installation. No more than $59 \%$ of the kinetic energy contained in an air-stream tube having the same cross section as a disc-shaped obstacle can be converted to useful work by the disc (the Lanchester-Betz-Joukowsky limit) (van Kulk, 2007). The actual conversion efficiency of this kinetic energy to electric power is likely to be lower than $30 \%(\mathrm{Bu}-$ sawon et al., 2005). With a conversion efficiency of $25 \%$, the wind turbines in Run $\mathrm{L}$ would provide about $158 \mathrm{EJ} / \mathrm{yr}$ (5 TW). In three other numerical experiments, the kinetic energy extracted by the wind turbines was either reduced or enhanced compared to Run L (e.g. reflecting the effects of lowering or raising the wind turbine spatial density). The computed electrical energy outputs are about 72,344 , and $603 \mathrm{EJ} / \mathrm{yr}$ (2.3, 11 and $19 \mathrm{TW})$ in Run VL, H, and VH, respectively. The offshore shallow ocean installations provide about 96 and $30 \mathrm{EJ} / \mathrm{yr}$ (3.0 and $0.95 \mathrm{TW}$ ) in Run $\mathrm{OH}$ and OL, respectively.

The computed air temperature over the installation regions in Run $\mathrm{L}$ is elevated by more than $1^{\circ} \mathrm{C}$ in the lowest model layer ( $\sim 30 \mathrm{~m}$ thick at sea level) in many regions (Fig. 2), but the increase, averaged over the entire global land surface, is only about $0.15^{\circ} \mathrm{C}$. Although the surface air temperature change is dominated by the increase over the wind turbineinstalled areas (Fig. 1), the changes go well beyond these areas (Fig. 2). The frequency distributions for temperature 

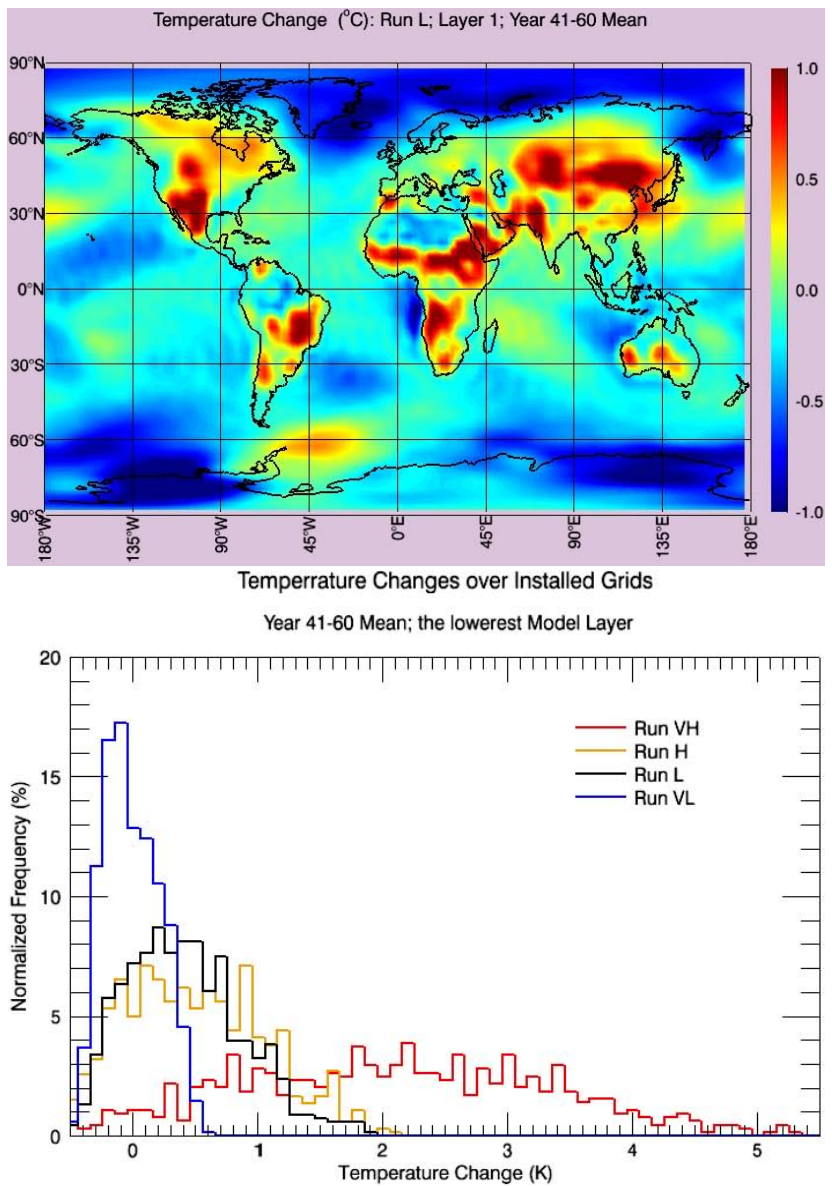

Fig. 2. Temperature changes (Run L minus reference, REF) in the lowest model layer resulting from large-scale deployment of wind turbines over land sufficient to generate $158 \mathrm{EJ} / \mathrm{year}$ of electric power (upper panel); and normalized frequency of temperature changes over the installation regions in Runs $\mathrm{VH}, \mathrm{H}, \mathrm{L}$, and VL (lower panel). Both refer to averages over years 41-60.

changes for Run $\mathrm{L}$ and the other three land-based runs, are also shown in Fig. 2. The global land-average temperature changes are $0.05,0.16$, and $0.73^{\circ} \mathrm{C}$, respectively, for these three other land-based runs (VL, $\mathrm{H}$ and $\mathrm{VH}$ ). In all these runs, except for Run VL, the global patterns of these changes are consistent with Run L (Fig. 2). These patterns also have some similarities to the previous study by Keith et al. (2004) over land, but not over the oceans, since that study assumed fixed ocean temperatures.

The warming caused by the wind turbines is limited to the lowermost atmospheric layers (Fig. 3). Above the planetary boundary layer, a compensating cooling effect is expected and observed in many regions, because the turbulent transfer of heat from the surface to these higher layers is reduced. This should be contrasted to the relatively uniformly distributed warming throughout the troposphere induced by rising greenhouse gases (IPCC, 2007).

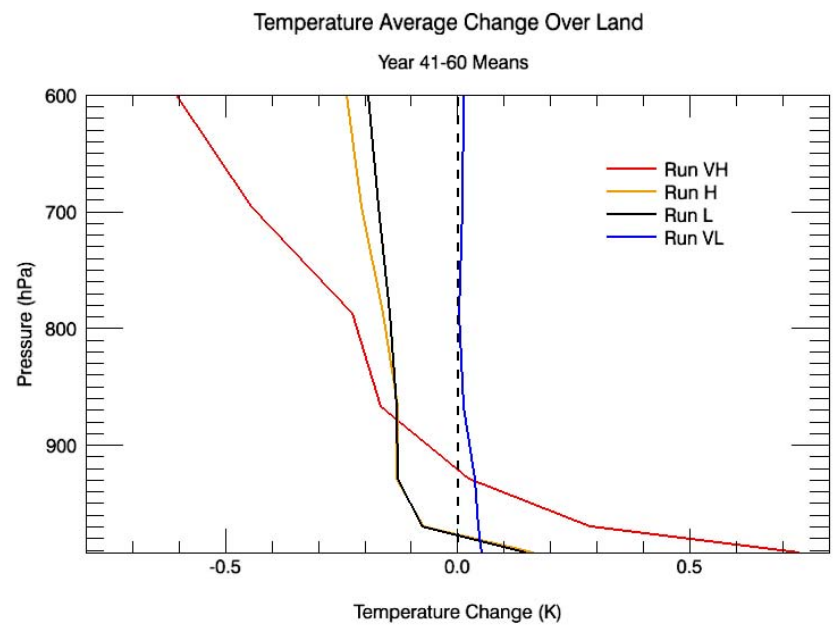

Fig. 3. Horizontally averaged temperature changes (relative to the reference, REF) over land in the 4 wind turbine installation runs. All data are 20-year means from year 41 to 60 .

Increasing surface roughness (to simulate the wind turbines) without significantly lowering the near-surface wind speed should increase near-surface turbulent latent and sensible heat transport and thus cool the surface. However, changes in surface roughness over a region with a very large width in the prevailing wind direction indeed cause a significant reduction in the wind speed. Our results suggest that the latter effect prevails over the majority of the installation regions (Fig. 4). When averaged over the land, the reductions of wind magnitude in the various land-installation cases display a similar vertical profile, with a peak in the second model layer above the surface (Fig. 4c). Note that the difference between Run L and Run H is defined more clearly in the wind reduction than in the temperature change (Fig. 3), implying that the temperature change is more closely related to the vertical turbulent heat exchange. The effect of wind reduction over the installed land regions appears to exceed the effect of the surface roughness increase. The wind reduction specifically weakens the near-surface vertical turbulent transport, and thus warms the surface (Fig. 5). Note that, like the effects on temperature, the effects of these wind turbine installations on wind magnitude, surface heat fluxes, spread well beyond the installation regions and often have opposite signs to those in the installation regions (Figs. 4 and 6). These long-range effects are likely to be very model-dependent. Dynamical mechanisms involving Rossby waves for long-range effects of large-scale changes in land surface friction have been proposed (Kirk-Davidoff and Keith, 2008). Long-range effects are also computed in climate model simulations where regional energy budgets are altered by aerosols (Wang, 2007). 

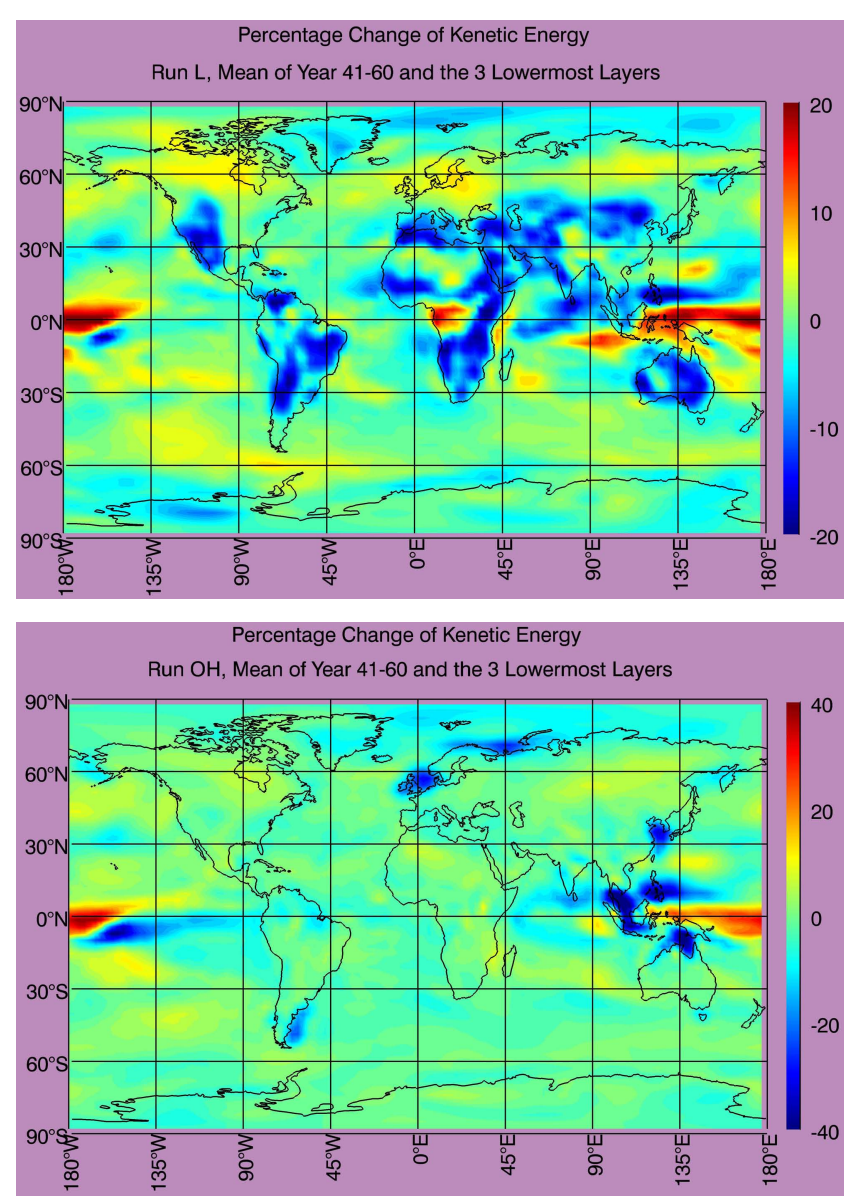

Averaged Wind Magnitude Change over Land

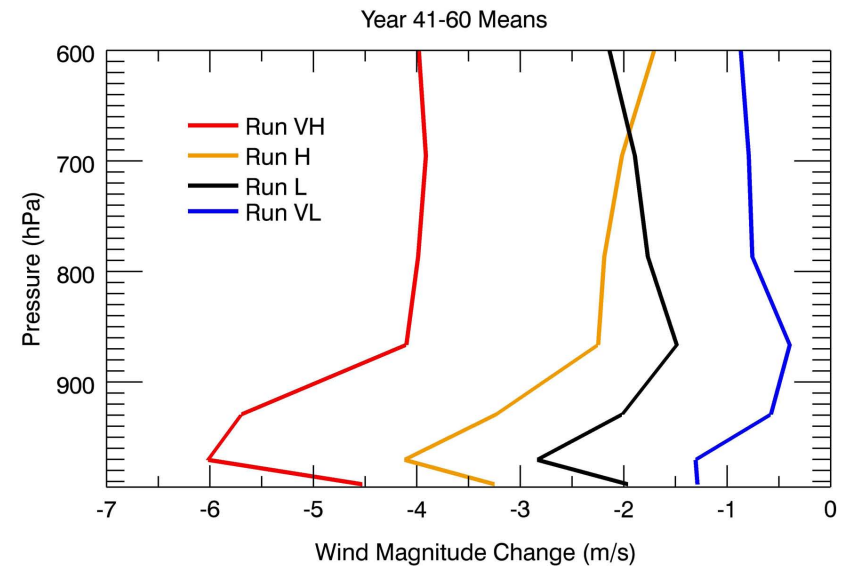

Fig. 4. The changes in the kinetic energy per unit mass are shown in the upper panel for Run L, and the middle panel for Run $\mathrm{OH}$. Also shown in the lower panel are the horizontally averaged wind magnitude changes (derived from the kinetic energy per unit mass change) over land in the 4 wind turbine installation runs. All data are 20-year means from year 41 to 60 .
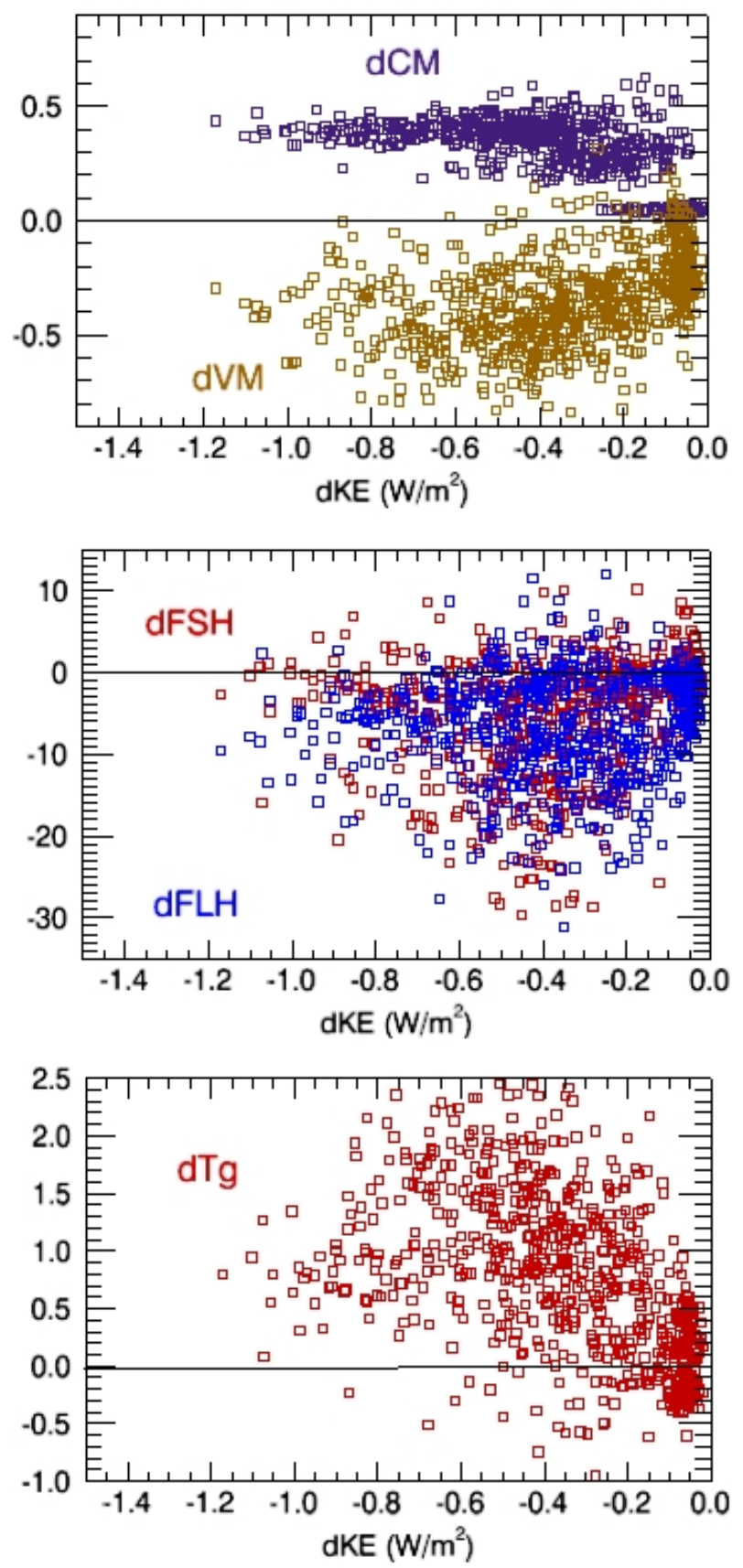

Fig. 5. Changes in surface momentum drag coefficient ( $d \mathrm{CM}$; unitless), wind magnitude $(d \mathrm{VM} ; \mathrm{m} / \mathrm{s})$, sensible $\left(d \mathrm{FSH} ; \mathrm{W} / \mathrm{m}^{2}\right)$ and latent $\left(d \mathrm{FLH} ; \mathrm{W} / \mathrm{m}^{2}\right)$ heat fluxes, and surface air temperature $(d \mathrm{Tg}$; $\mathrm{K})$ over the model grids where the kinetic energy losses $(d \mathrm{KE}$; $\mathrm{W} / \mathrm{m}^{2}$ ) due to wind turbines occur. Results shown are year 41-60 means of Run L minus Run REF. 

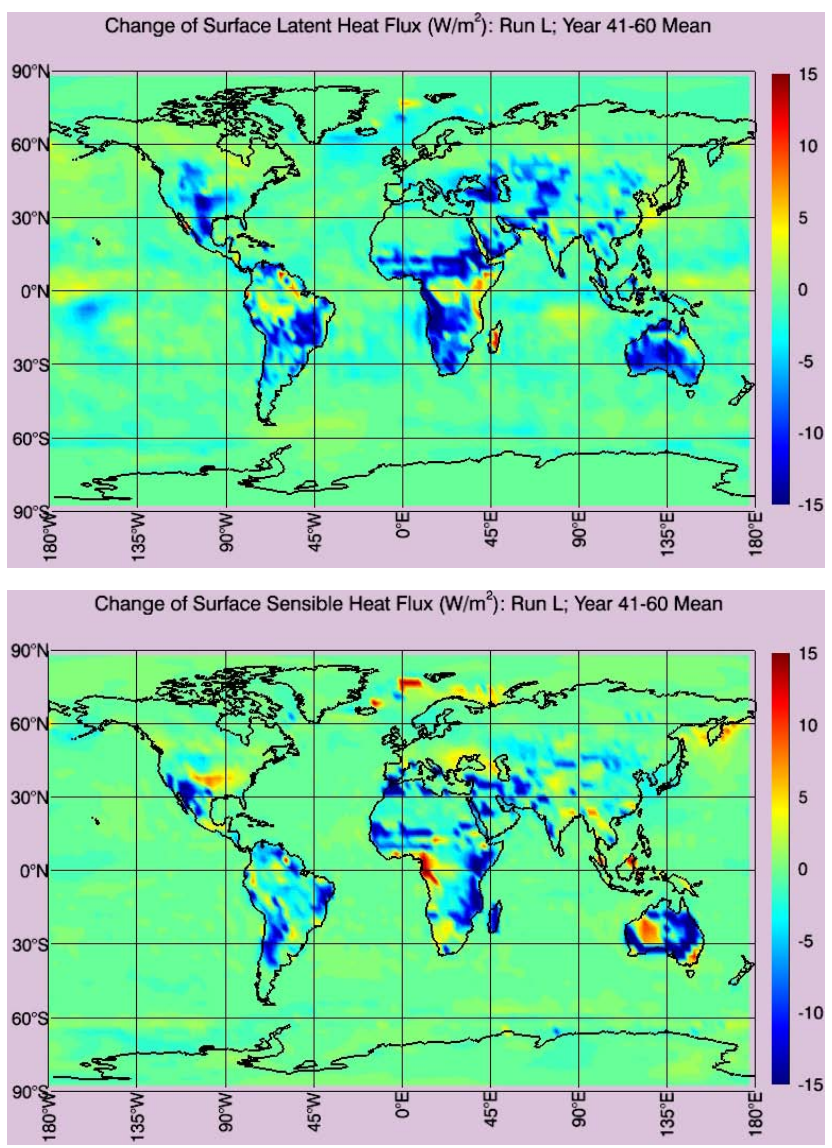

Fig. 6. Surface heat flux changes for Run L (Run L minus Run REF) for latent heat (upper panel) and sensible heat (lower panel) fluxes. Both panels are in $\mathrm{W} / \mathrm{m}^{2}$ and averaged over years 41-60.

Note that the fractional changes of surface drag in our two ocean-based runs using a slab ocean model are very high compared to the land cases, owing to the much higher intrinsic surface roughness over land than over ocean (Fig. 7). Therefore, in contrast to the land-based experiments, this substantial increase in surface drag in the ocean-based experiments creates much stronger turbulence that substantially opposes the wind reduction effect due to the roughness change. This leads to an enhancement in ocean-atmosphere heat fluxes, particularly latent heat fluxes, and thus to local cooling over almost all of the installation regions (Fig. 8). As in the land-based runs, the temperature changes in the coastal ocean-based runs also occur well beyond the installation regions with similar vertical profiles (not shown) to Fig. 3, but with opposite signs. Note that these results in these two ocean runs are likely not reliable, since they are dependent on the single CCM3 model option available to us for making the changes to ocean surface properties necessary to simulate the drag effects of wind turbines over water. These results might also differ from those derived using a full ocean GCM that allows changes in oceanic circulation.

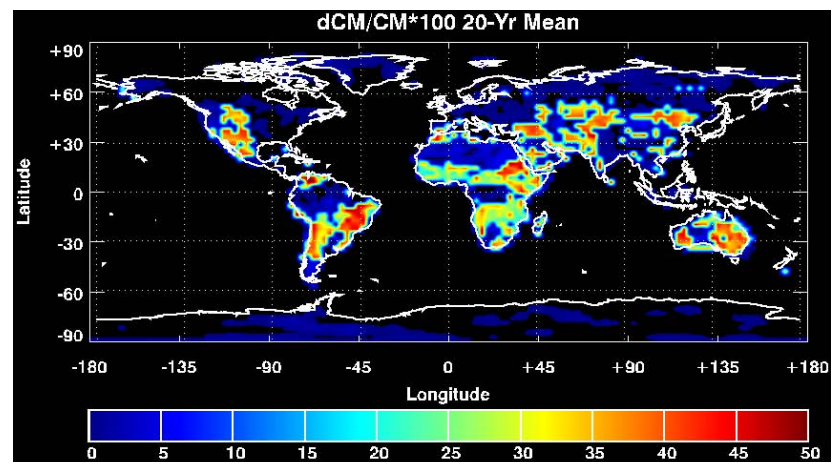

CD (10m) Momentum for Neutral Condition

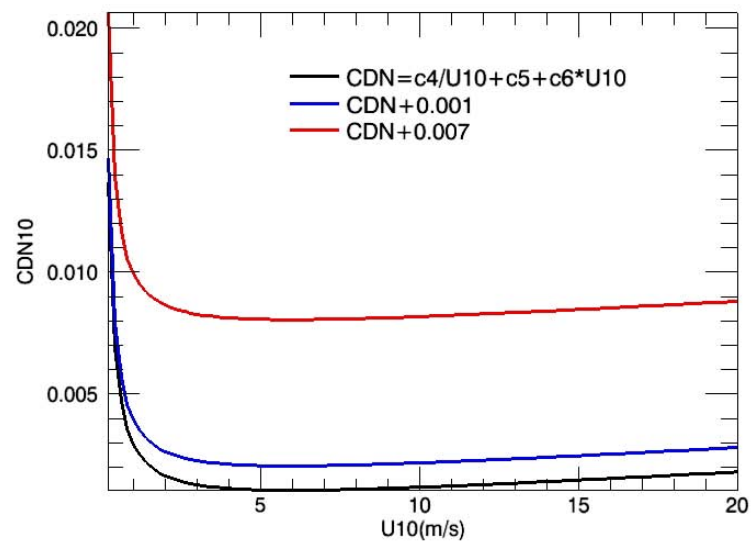

Fig. 7. Percentage changes of surface momentum drag coefficient $\left(d \mathrm{CM} / \mathrm{CM}^{*} 100\right)$ due to the simulated wind turbines over the land (upper panel); and surface momentum coefficients (CDN10) without (black line) and with (Run OL, blue line; Run OH, red line) the simulated wind turbines over the ocean (lower panel).

The spatially extensive changes in temperatures and surface heat fluxes for the land installations are sufficient to affect the global distributions of cloud cover, especially the lower clouds (not shown), and precipitation (Fig. 9). The rates of convective precipitation (Fig. 9) are generally reduced in the Northern Hemisphere and enhanced in the Southern Hemisphere, symptomatic of a shift in the atmospheric Hadley Circulation (Wang, 2007, 2009), reflecting an alteration to the large-scale circulation by the surface roughness changes caused by wind turbines (see e.g. KirkDavidoff and Keith, 2008). In the mid-latitudes, especially in the Northern Hemisphere, changes in large-scale precipitation also appear (Fig. 9), indicating an impact on mid-latitude weather systems. Although the changes in local convective and large-scale precipitation exceed 10\% in some areas, the global average changes are not very large.

To investigate the issue of wind variability leading to intermittency in wind power generation, we show in Fig. 10 the average and standard deviation of the monthly-mean wind power consumption $(D \mathrm{KE}=d \mathrm{KE} / d t$ in $\mathrm{TW}$, see Eq. 1) for each month of the year and for each continent over 


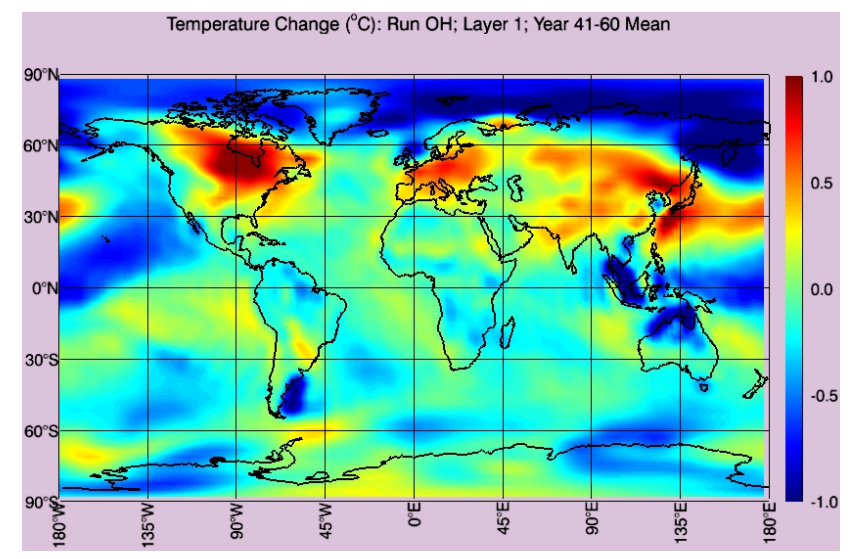

Fig. 8. Same as Fig. 2 (upper panel) but for Run $\mathrm{OH}$.

the last 20 years of Run L. Also shown is the time series of these monthly-means over the last 20 years. Dividing $D K E$ by 4 for a $25 \%$ conversion efficiency, the 20 -year average generated electrical power over each continent is 0.57 (North America), $0.72 \mathrm{TW}$ (South America), $1.28 \mathrm{TW}$ (Africa/Middle East), 0.63 TW (Australia), and $1.29 \mathrm{TW}$ (Eurasia). However, quite apart from the well-known dayto-night and day-to-day intermittency of wind turbines, from Fig. 10 there are very large (up to a factor of 2) and geographically extensive seasonal variations especially over North and South America and Africa/Middle East. Unfortunately the months of minimum generation usually coincide with maximum demand for air conditioning. In an electrical generation system dominated by wind turbines, reliability of supply cannot therefore be achieved simply by long-distance power transmission over these continents.

\section{Conclusions}

Meeting future world energy needs while addressing climate change requires large-scale deployment of low or zero GHG emission technologies such as wind energy. We used a threedimensional climate model to simulate the potential climate effects associated with installation of wind-powered generators over vast areas of land and ocean. Using wind turbines to meet $10 \%$ or more of global energy demand in 2100 could cause surface warming exceeding $1{ }^{\circ} \mathrm{C}$ over land installations. Significant warming and cooling remote from the installations, and alterations of the global distributions of rainfall and clouds also occur.

Our ocean results indicating cooling over the installation regions and warming and cooling elsewhere are interesting, but suspect due to the unrealistic increases in surface drag needed to extract the target wind power. Specific new and realistic parameterizations for simulating the effects of wind turbines over the ocean will need to be developed and applied in general circulation models before reliable conclusions can
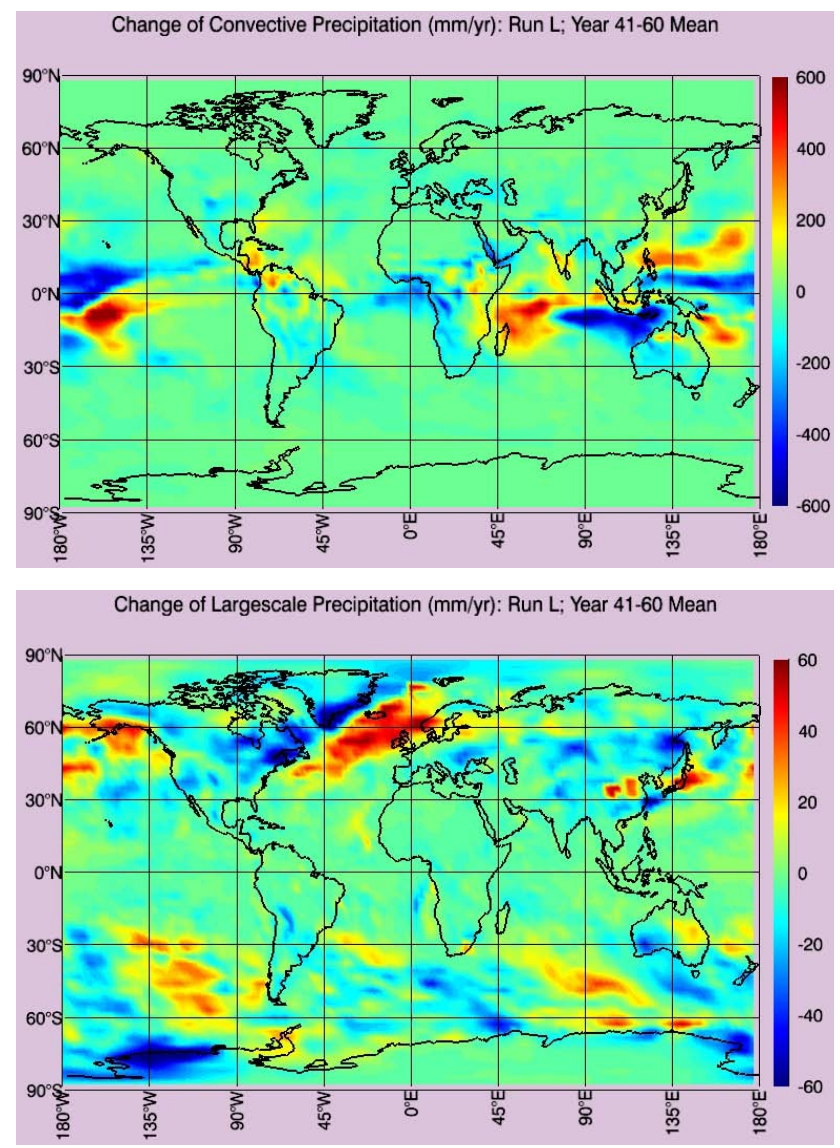

Fig. 9. Precipitation changes (Run L minus Run REF) for: convective precipitation (upper panel), and large-scale precipitation (lower panel). Both are in $\mathrm{mm} / \mathrm{yr}$ and averaged over years 41-60.

be reached. Future advances in floating turbine technology might enable the installation of wind turbines over oceans at depths exceeding our assumed 200-m maximum depth range, presuming that the issue of the needed long-range electricity transmission is resolved.

Installation of wind turbines over land areas that have alternative spatial extents, topographies and hydrological properties would produce different, but presumably still significant, climate effects. Due to the computed nonlinearity between the changes in surface roughness and the climate response, defining the optimal deployment of wind turbines is challenging. Climatic effects increase with power generated and decrease with conversion efficiency, putting aside the potential environmental effects for instance on birds and weather radar as well as on ambient noise levels. Also, for the widely spaced wind turbines simulated in our runs, the environmental effects appear small when they are generating less than $1 \mathrm{TW}$ globally even with current technologies.

Our results should be fairly robust to assumptions about the specific wind turbine technologies utilized. Increasing their efficiencies from $25 \%$ to $35 \%$ helps to lower, but does 

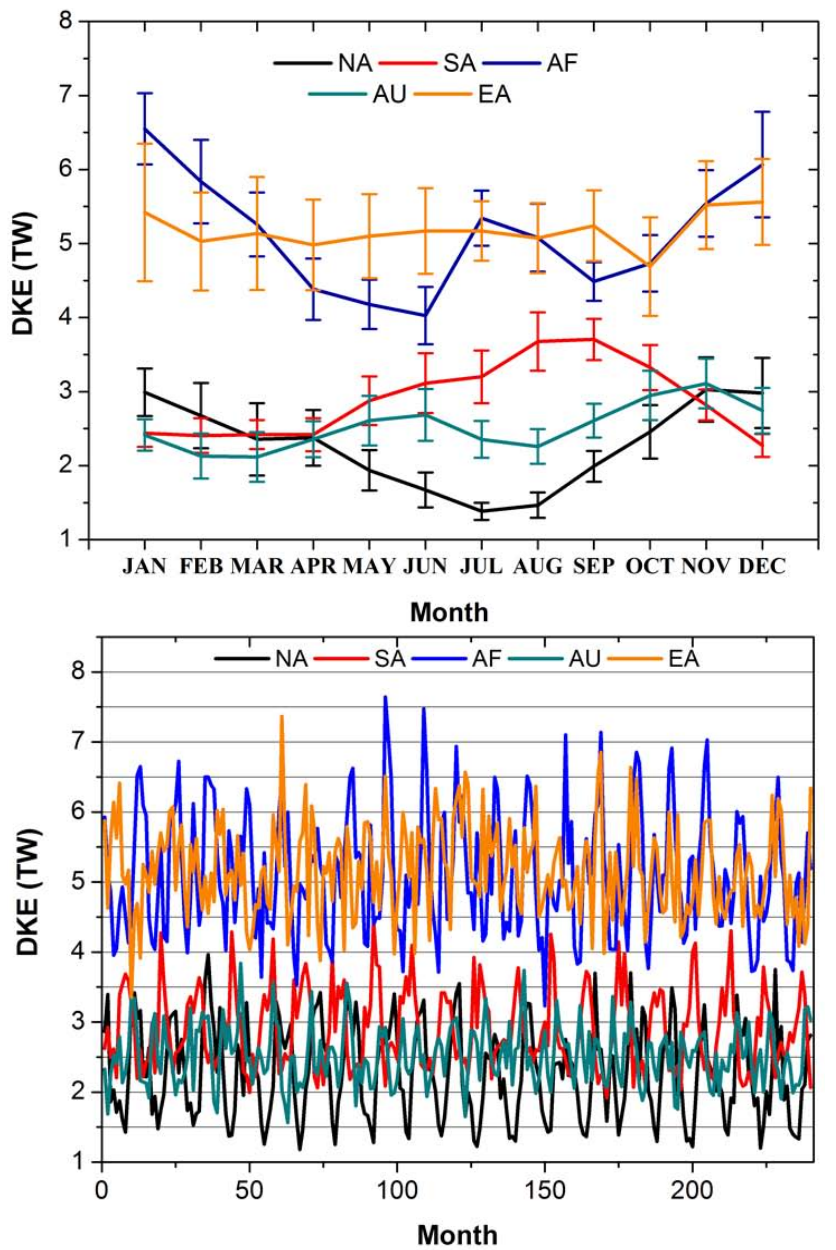

Fig. 10. Twenty-year (years 41-60) averages and standard deviations (upper panel), and all values (lower panel), of the monthly mean wind power consumption $(D \mathrm{KE}=d \mathrm{KE} / d t, \mathrm{Eq} .1)$ by simulated wind turbines installed in various continents: North America (NA), South America (SA), Africa and Middle East (AF), Australia (AU), and Eurasia (EA).

not remove the calculated climate effects. Our results are dependent upon the realism of the land surface and atmospheric boundary layer in our chosen climate model, and investigations with alternative models, including higher-resolution climate models with fully dynamical three-dimensional oceans are warranted. Our method involving varying the surface roughness has been shown to capture certain features of the effects of turbines on the local wind using mesoscale models (Frandsen, 1992; Vermeer et al., 2003). However, this method cannot explicitly resolve the detailed vertical wind profiles affected by atmospheric stability or wind shear that are clearly subgrid scale processes in our model (Vermeer et al., 2003; Lange and Focken, 2005). Appropriate field experiments to test our conclusions, and to explore better ways for simulating wind turbines in models, are also required.
Finally, intermittency of wind power on daily, monthly and longer time scales as computed in these simulations and inferred from meteorological observations, poses a demand for one or more options to ensure reliability, including backup generation capacity, very long distance power transmission lines, and on-site energy storage, each with specific economic and/or technological challenges

Acknowledgements. We thank the National Center for Atmospheric Research (NCAR) for making the code and driving data of the CCM3 model available to us. This research was supported by the US Department of Energy (DOE-BER and DOE-NREL), and the Corporate, Governmental, and Foundation sponsors of the MIT Joint Program on the Science and Policy of Global Change.

Edited by: W. E. Asher

\section{References}

Archer, C. L. and Jacobson, M. Z.: Spatial and temporal distributions of US winds and wind power at $80 \mathrm{~m}$ derived from measurements, J. Geophys. Res., 108, 4289, doi:10.1029/2002JD002076, 2003.

Baidya Roy, S., Pacala, S. W., and Walko, R. L.: Can large wind farms affect local meteorology?, J. Geophys. Res., 109, D19101, doi:10.1029/2004JD004763, 2004.

Busawon, K., Dodson, L., and Jovanovic, M.: Estimation of the power coefficient in a wind conversion system, Proc. 44th IEEE Conf. on Decision and Control, and the European Control Conf. 2005, Seville, Spain, 12-15 December, 3450-3455, 2005.

Carter, H. G.: Wind as motive power for electrical generators, Mon. Wea. Rev., 54, 374-376, 1926.

Crespo, A., Hernandez, J. H., and Frandsen, S.: Survey of modeling methods for wind turbine wakes and wind farms, Wind Energy, 2, 1-24, 1999.

Frandsen, S.: On the wind speed reduction in the center of large clusters of wind turbines, J. Wind Eng. Indus. Aerodyn., 39, 251$265,1992$.

Hewson, E. W.: Generation of power from the wind, Bull. Amer. Meteor. Soc., 56, 660-675, 1975.

IPCC: Climate Change 2007: The Physical Science Basis, Contribution of Working Group I to the Fourth Assessment Report of the Intergovernmental Panel on Climate Change, edited by: Solomon, S., Qin, D., Manning, M., Chen, Z. Marquis, M., Averyt, K. B., Tignor, M., and Miller, H. L., in: Cambridge University Press, Cambridge, UK and New York, NY, USA, 996 pp., 2007.

Keith, D. W., DeCarolis, J. F., Denkenberger, D. C., Lenschow, D. H., Malyshev, S. L., Pacala, S. N., and Rasch, P. J.: The influence of large-scale wind power on global climate, P. Natl. Acad. Sci. USA, 101, 16115-16120, 2004.

Kiehl, J. T., Hack, J. J., Bonan, G. B., Boville, B. A., Williams, D. L., and Rasch, P. J.: The National Center for Atmospheric Research Community Climate Model: CCM3, J. Climate, 11, 1131- 1149, 1998.

Kirk-Davidoff, D. B. and Keith, D. W.: On the Climate Impact of Surface Roughness Anomalies, J. Atmos. Sci., 65, 2215-2234, doi:10.1175/2007JAS2509.1, 2008. 
van Kulk, G. A. M.: The Lanchester-Betz-Joukowsky limit, Wind Energy, 10, 289-291, 2007..

Lange, M. and Focken, U.: Physical Approach to Short-Term Wind Power Prediction, Springer, Berlin, 2006.

Lorenz, E. N.: The Nature and Theory of the General Circulation of the Atmosphere, WMO, Geneva, 161 pp., 1967.

Peixoto, J. P. and Oort, A. H.: Physics of Climate, Amer. Inst. Phys., New York, 520 pp., 1992.

Reilly, J. and Paltsev, S.: Biomass Energy and Competition for Land, Report No. 145, MIT Joint Program on the Science and Policy of Global Change, Cambridge, MA., online available at: http://web.mit.edu/globalchange/www/MITJPSPGC_Rpt145. pdf, 2007.
Stull, R. B.: An Introduction to Boundary Layer Meteorology, Kluwer Acad. Pub., Dordrecht, 666 pp., 1988.

Vermeer, L. J., Sorensen, J. N., and Crespo, A.: Wind turbine wake aerodynamics, Prog. Aerospace Sci., 39, 467-510, 2003.

Wang, C.: Impact of direct radiative forcing of black carbon aerosols on tropical convective precipitation, Geophys. Res. Lett., 34, L05709, doi:10.1029/2006GL028416, 2007.

Wang, C.: The sensitivity of tropical convective precipitation to the direct radiative forcings of black carbon aerosols emitted from major regions, Ann. Geophys., 27, 3705-3711, 2009, http://www.ann-geophys.net/27/3705/2009/. 